\title{
O Fórum de Discussão como Instrumento Avaliativo de Aprendizagem
}

\author{
The Discussion Forum as a Learning Assessment \\ Tool
}

\author{
ALEXANDRA DA COSTA SOUZA MARTINS \\ SENAC de Brasília \\ LUCICLEIDE ARAÚJO DE SOUSA ALVES \\ Universidade Católica de Brasília
}

\begin{abstract}
Resumo: O objetivo deste estudo é analisar o fórum de discussão como instrumento avaliativo, segundo a percepção de estudantes e tutores de cursos na modalidade de educação a distância online. Para tanto, adotou-se pesquisa exploratória por meio de abordagem qualitativa, utilizando como instrumento o questionário misto e para análise deste, a técnica de Análise de Conteúdo. Ao longo da Discussão são apresentados critérios de avaliação em fórum de discussão considerados mais apropriados, segundo a percepção dos participantes do estudo, além de uma listagem de atributos ligados a aspectos positivos e negativos, os quais foram organizados em grandes áreas: aprendizagem, atuação, interação/participação, design instrucional e relação entre os participantes. Os resultados demonstraram que o fórum de discussão, embora tenha alguns aspectos considerados negativos, é um bom instrumento de avaliação que muito pode colaborar para maximizar a qualidade da aprendizagem dos estudantes.
\end{abstract}

Palavras- chave: Educação a distância. Online. Fórum. Avaliação. Listagem de atributos.

\begin{abstract}
The objective of this study is to analyze the discussion forum as an assessment tool, according to the perceptions of students and tutors of online and distance learning education courses. With this goal in mind, an exploratory research was adopted by means of a qualitative approach. A mixed questionnaire was used as a tool and a content analysis was later conducted. Throughout the Discussion, the study presents evaluation criteria in the discussion forum that is considered most appropriate, as perceived by study participants, as well as an attribute list linked to positive and negative aspects, which were organized in major areas: learning, performance, interaction / participation, instructional design and relationship among participants. The results showed that the discussion forum, despite some considered negative aspects, is a good assessment tool that can greatly contribute to maximize student's learning.
\end{abstract}

Keywords: Distance education. Online Forum. Assessment. Attribute List.

MARTINS, Alexandra da Costa Souza; ARAÚJO, Lucicleide de Sousa Alves. O Fórum de Discussão como Instrumento Avaliativo da Aprendizagem. Informática na Educação: teoria \& prática, Porto Alegre, v. 19, n. 2, p. 106-122, jun./set. 2016. 


\section{I ntrodução}

O mundo globalizado liga e religa as pessoas, possibilita troca de informações, experiências, interações, em um processo constante de aprendizagem a qualquer hora e em qualquer lugar, por meio dos ambientes virtuais de aprendizagem (AVA), os quais possuem distintos instrumentos de avaliação, dentre eles o fórum de discussão, que será o foco desse estudo. Esse instrumento, por sua vez, deve ser bem explorado entre os pares (tutores e estudantes) para garantir as condições necessárias de que o processo de ensino e aprendizagem por meio da ferramenta fórum de discussão e na modalidade de educação online favoreça e potencialize a aprendizagem dos estudantes com qualidade. Esta preocupação remete à necessidade de acompanhamento mediante uma "presença virtual" por parte dos tutores em relação ao processo de construção e desenvolvimento de conhecimentos por parte dos estudantes nestes espaços concebidos na virtualidade.

Fóruns de discussão são espaços privilegiados para o exercício de relações "dialógicas" abertas e plurais sobre temáticas propostas, troca de experiências e feedbacks (PALOFF; PRATT, 2004) entre o professor mediador e estudantes e entre os estudantes.

As interações ocorrentes nestes espaços intersubjetivos de diálogos e trocas de conhecimentos permitem aos sujeitos ativos estabelecerem as pontes necessárias entre os saberes que já conhecem, com os ainda considerados necessários e importantes a serem apreendidos. Uma vez que tudo o que se fala é registrado, o que torna o fórum também instrumento de avaliação do percurso e da aprendizagem dos estudantes e muito pode contribuir na percepção dos estudantes e professores em relação aos avanços concebidos durante os processos construtivos de conhecimento pertinente.

Este modo de avaliar os estudantes a partir de seus próprios saberes escritos, por meio de apontamentos por parte do mediador em relação aos conhecimentos apreendidos ou não podem promover aos alunos deslocamentos quanto ao nível de conhecimentos anteriormente iniciados para um outro. Assim, o fórum de discussões funcionaria neste sentido como um termômetro tanto para o educador, que atento ao que emerge nestes espaços estaria buscando outras inovadoras formas de potencializar situações que levem o aluno a aprender, bem como para o aluno que estaria se autoavaliando o tempo todo durante o seu processo construtivo de conhecimento.

É fundamental, nesse sentido a formação do Tutor a Distância com ênfase na mediação eficaz de fóruns de discussão avaliativos para que o processo de ensino e aprendizagem promovidos a partir dessa ferramenta assíncrona fórum de discussão se construa positivamente e a aprendizagem aconteça por parte dos estudantes. Quando o tutor reconhece o potencial dessa ferramenta, tem presença virtual ativa e sabe da importância de seu papel como mediador ele passa a criar situações didáticas que possibilitam o envolvimento dos alunos nas discussões, intensificando-se assim maior interação e interatividade entre os participantes e uma maior qualidade nas trocas intersubjetivas. Dessa forma constrói-se um espaço favorável para que a aprendizagem de fato aconteça. Agindo assim, a mediação traz resultados significativos ao aprendizado do aluno e o papel da tutoria torna-se indispensável. 
Nessa perspectiva, cabe ainda ressaltar que o estudo sobre fórum de discussão tem sido estimulado pela utilização de cursos online no cenário educacional brasileiro, que o tem utilizado como estratégia de avaliação da aprendizagem.

No que tange à definição dos objetivos, essa foi impulsionada pelas experiências profissionais vividas pelas autoras do estudo em atuações de tutoria e coordenação pedagógica em cursos de pós-graduação na modalidade EaD online, as quais observaram o uso cada vez mais frequente do fórum de discussão como instrumento avaliativo e, por se tratar de uma avaliação prioritariamente subjetiva, foi despertado o interesse em analisar o referido instrumento sob a ótica de tutores e acadêmicos. Assim, o objetivo geral é analisar o fórum de discussão como instrumento avaliativo, segundo a percepção de estudantes e tutores de cursos na modalidade EaD online. Quanto aos objetivos específicos, a proposta é construir listagem de atributos considerados positivos e negativos no processo avaliativo realizado em fórum de discussão, segundo a percepção de estudantes e tutores e identificar critérios considerados mais apropriados para avaliação por meio de fóruns de discussão.

Ao longo do estudo é apresentada uma listagem de atributos ligados a aspectos positivos e negativos, os quais foram organizados em grandes áreas: aprendizagem, atuação, interação/participação, design instrucional e relação interpessoal.

Ressalta-se, ainda, que a opção por analisar o fórum em detrimento de outros recursos disponíveis nos ambientes virtuais de aprendizagem se deve ao fato da intensa utilização da ferramenta não apenas para realização de atividades, mas também para a avaliação da aprendizagem. É também dado enfoque à dinamicidade para utilização do fórum de discussão, especialmente por sua contribuição por meio de aprendizagem dialógica e colaborativa.

As seguintes questões de pesquisa foram investigadas:

- Segundo a percepção de tutores e acadêmicos o fórum de discussão é considerado uma boa ferramenta para avaliação da aprendizagem?

- Qual a percepção dos tutores a respeito dos critérios de avaliação que devem ser estabelecidos para avaliação da aprendizagem por meio do fórum de discussão?

- Qual a percepção dos acadêmicos a respeito dos critérios de avaliação considerados mais apropriados para avaliação da aprendizagem por meio do fórum de discussão?

- Quais aspectos positivos podem ser citados a respeito da utilização do fórum de discussão como instrumento de avaliação da aprendizagem?

- Quais aspectos negativos ou que precisam ser mais bem explorados a respeito da utilização do fórum de discussão como instrumento de avaliação da aprendizagem?

\section{Metodologia}

Para realização da pesquisa, adotou-se pesquisa exploratória por meio da abordagem qualitativa. 


\subsection{Participantes}

Participaram do estudo dois grupos distintos, sendo um de tutores e outro de alunos, com respectivas experiências profissionais e acadêmicas em cursos de pós-graduação na modalidade a distância online (Docência no Ensino Superior, Gestão Escolar, Educação a Distância, Docência para a Educação Profissional, PROFORM (Programa de Formação de Professores/Licenciatura Plena) e Especialização em Governança de TI) de uma instituição de ensino da rede particular reconhecida nacionalmente.

No grupo de tutores participaram sete pessoas. Quanto ao gênero, três eram do sexo feminino e quatro do sexo masculino, com idade entre 39 e 60 anos e o tempo de atuação como tutores de curso de pós-graduação a distância foi em média de sete anos. Com relação à formação acadêmica, um possuía especialização, três eram mestres, dois estavam cursando o doutorado e um possuía o título de doutor.

No grupo de alunos participaram onze pessoas. Quanto ao gênero, dez eram do sexo feminino e um do sexo masculino, com idade entre 32 e 66 anos. Com relação à formação acadêmica, oito eram especialistas, dois possuíam o título de mestre e um estava cursando o mestrado.

\subsection{Instrumento e Procedimentos}

Utilizou-se como instrumento o questionário misto, contendo perguntas abertas e fechadas relacionadas aos dados pessoais dos respondentes e sobre o fórum de discussão como instrumento avaliativo. Os questionários foram enviados aos participantes por e-mail e devolvidos pelo mesmo canal de comunicação.

\subsection{Análise de Dados}

Para análise dos dados realizou-se a técnica de Análise de Conteúdo fundamentando-se em Creswell (2007) e Franco (2005). Ao longo da análise, para se referir aos participantes do grupo de tutores, será adotada a sigla T (Tutor) seguida de uma letra utilizada para diferenciálos. Para se referir aos participantes do grupo de alunos será utilizada a letra A (Acadêmico) seguida de um número utilizado para diferenciá-los.

\section{Avaliação da Aprendizagem na EaD}

A educação à distância (EAD) no Brasil atravessa décadas marcando sua história de sucesso, levando educação, através da mídia impressa, do rádio, da televisão, às demandas da população menos favorecidas das regiões brasileiras.

O crescimento e a expansão da EAD online por meio dos ambientes virtuais de aprendizagem possibilitam que pessoas do país inteiro tenham oportunidades de completar seus estudos sem saírem de casa, ter maior oportunidade de acesso à educação superior, além de conseguirem se atualizar e ampliar seus currículos com a realização de novos cursos. 
Com a chegada dos computadores ao Brasil, por meio das universidades, na década de 1970, a Internet ajuda na consolidação e propagação da educação à distância online, por permitir a conectividade entre as pessoas do mundo em um outro nível de realidade, a realidade virtual. Por meio da Internet a EaD se potencializa, pois a informação, através da rede mundial de computadores é disseminada mundialmente e possibilita meios para colaboração, interação entre as pessoas, e emana novos espaços para a comunicação, organização, socialização, troca de informações, de conhecimento e de avaliação dos processos de educação no que diz respeito à aprendizagem dos estudantes.

De acordo com o Artigo 1을 Decreto 5.622/2005 a educação a distância é definida como:

Mediação didático-pedagógica nos processos de ensino e aprendizagem que ocorre com a utilização de meios e tecnologias de informação e comunicação, com estudantes e professores desenvolvendo atividades educativas em lugares ou tempos diversos (BRASIL, 2005, p. 1).

Para Moran (2003) esta modalidade de educação online é realizada com o uso de procedimentos de ensino-aprendizagem desenvolvidos por meios telemáticos variados: internet, videoconferência, teleconferência e outros.

O Ministério da Educação, com o objetivo de maximizar a qualidade dos cursos oferecidos na modalidade EaD definiu, por meio dos Referenciais de Qualidade para a Educação Superior a Distância, princípios, diretrizes e critérios que devem constar no Projeto Político Pedagógico da instituição, sendo: “Concepção de educação e currículo no processo de ensino e aprendizagem; sistemas de comunicação; material didático; avaliação; equipe multidisciplinar; infraestrutura de apoio; gestão acadêmico-administrativa e sustentabilidade financeira". (BRASIL, 2007, p. 7)

Os Referenciais de Qualidade para a Educação Superior a Distância definem ainda que "não há um modelo único de educação à distância. Os programas podem apresentar diferentes desenhos e múltiplas combinações de linguagens e recursos educacionais e tecnológicos" (BRASIL, 2007, p. 7). Nessa perspectiva, Salvucci, Lisboa e Mendes (2012) ressaltam que o ensino virtual deve incluir a multidimensionalidade dos recursos e ferramentas tecnológicas. Além disso, os autores sinalizam que há necessidade de prever no planejamento condições para proporcionar autonomia do aluno, exploração do material didático de diferentes formas, conhecer os recursos disponíveis em cada ferramenta, bem como se atualizar com relação às melhores técnicas de interação e mediação.

A consolidação da EaD no cenário educacional brasileiro vem provocando mudanças de concepções. Não somente os alunos estão se adaptando às novas metodologias de ensino, mas também os professores precisaram revitalizar seus procedimentos didáticos. Como consequência inevitável, novas competências são exigidas deste profissional, como: ser proativo, ter habilidades para comunicação prioritariamente por meio da escrita, viabilizar condições que permitam a aprendizagem do aluno utilizando instrumentos dos ambientes virtuais de aprendizagem, definir critérios de avaliação transparentes e bem consolidados para avaliações subjetivas e acompanhar diariamente as participações e o desenvolvimento dos alunos, interagindo sempre que possível e/ou necessário. 
Para Dias e Leite (2010) essas novas exigências reforçam a ideia de que o professor deve deixar para trás a mera função de transmissor de saberes. Tem-se, ainda, mudança de posicionamento dos alunos, dos quais se espera postura mais autônoma no processo de aprendizagem e exploração das tecnologias da informação e comunicação com notável destaque para a web. Salvucci, Lisboa e Mendes (2012) sinalizam que o docente, ao realizar o seu planejamento, deve fazer a junção de conteúdos e metodologias que viabilizem estratégias apropriadas, instrumentos tecnológicos adequados para aprofundamentos de conceitos, além de viabilizar condições para que o aluno alcance os níveis de compreensão desejados.

Esse contexto provoca também novas reflexões a respeito do processo de avaliação mais apropriado para cursos online. Na visão de Hoffmann (2005) a avaliação é necessária à educação, no entanto, deve ser executada por meio de estratégias dinâmicas, com realização de situações problema, questionamentos, abandonando procedimentos tradicionais em detrimento de ações que possibilitem a reflexão e a presença de um aluno mais proativo em seu processo de aprendizagem.

A avaliação na EaD, assim como na educação presencial, não deixa de ser complexa e está baseada na Lei 9.394/96, a qual sinaliza a "prevalência dos aspectos qualitativos sobre os quantitativos e dos resultados ao longo do período sobre os de eventuais provas finais" (BRASIL, 1996). Cabe ressaltar também que o Artigo 4ㅇ do Decreto 5.622/2005 regulamenta o Artigo $80^{\circ}$ da referida Lei, o qual sinaliza que "a avaliação do desempenho do estudante para fins de promoção, conclusão de estudos e obtenção de diplomas ou certificados dar-se-á no processo, mediante: cumprimento das atividades programadas; e II - realização de exames presenciais" (BRASIL, 2005). Tendo em vista as bases normativas anteriormente mencionadas, pode-se considerar que o fórum de discussão é uma ferramenta que permite prevalência dos aspectos qualitativos pelo caráter subjetivo imbuído em sua proposta.

Considera-se que um dos aspectos mais positivos da utilização do fórum de discussão enquanto instrumento avaliativo é a promoção da aprendizagem por meio da relação entre os sujeitos na dinâmica do ensino e da aprendizagem. Nessa perspectiva, Kratochwill (2009) sinaliza que no processo de construção do conhecimento a interação entre os sujeitos é precípua. Apoiada na concepção vigotskiana a autora destaca que a linguagem, por meio das trocas intersubjetivas de conhecimentos entre os pares (professor/estudantes, estudantes/estudantes) viabiliza a construção do conhecimento, tendo em vista que enfatiza a relação entre os sujeitos, a relação com o conteúdo e com o meio. Silva (2003) apresenta abordagem semelhante, no entanto com foco no diálogo, sinalizando que esse promove o encontro entre professores e alunos, junção de ideias e reconstrução de conceitos. Já Dias e Leite (2010) defendem que outro aspecto positivo do fórum de discussão é a possibilidade de viabilizar a aprendizagem colaborativa e destacam que a interação permite o compartilhamento de pontos de vista distintos a respeito de um tema em particular.

Em resumo, a avaliação por meio do fórum de discussão é um processo complexo, dinâmico e dialógico, que objetiva potencializar a aprendizagem colaborativa por meio da interação, trocas de conhecimento, visando garantir que o processo de ensino e aprendizagem 
possibilite que os sujeitos se apropriem da cultura, desenvolvam-se e se transformem permanentemente.

\section{Resultados e Discussão}

Os resultados foram organizados em quatro temas: fórum de discussão como ferramenta para avaliação da aprendizagem; critérios para avaliação da aprendizagem por meio do fórum de discussão; aspectos positivos a respeito da utilização do fórum de discussão como instrumento de avaliação da aprendizagem; e aspectos negativos ou que precisam ser mais bem explorados a respeito da utilização do fórum de discussão como instrumento de avaliação da aprendizagem. Para melhor análise dos aspectos positivos e negativos a respeito da utilização do fórum de discussão, os dados foram apresentados em quadros, cujas respostas dos participantes foram separadas por assuntos semelhantes.

\subsection{Fórum de Discussão como Ferramenta para Avaliação da Aprendizagem}

No grupo de tutores pesquisados, somente um não considerou o fórum um bom instrumento para avaliação, justificando que “o fórum é muito bom para tirar dúvidas e troca de ideias, mas não para avaliação de desempenho do aluno" (TC).

Por outro lado, seis tutores consideraram o fórum de discussão uma boa ferramenta de avaliação da aprendizagem e apresentaram distintas justificativas: possibilidade do aluno expressar suas dúvidas e expor conhecimentos sobre o assunto abordado; permite ao tutor perceber o nível de conhecimento e desenvolvimento do aluno, bem como avaliar se as técnicas abordadas estão adequadas; possibilidade, por meio de diálogos, de identificar o aprofundamento que o aluno fez em seus estudos sobre o assunto; oportuniza espaço para debates e discussões. Um dos respondentes sinalizou a importância de o fórum de discussão, enquanto instrumento de avaliação, ser bem explorado e dos critérios e orientações referentes ao que se espera do aluno ser apresentado com objetividade e transparência:

Considero o fórum uma importante ferramenta de discussão e interação entre estudantes e destes com a docência na EAD. No entanto, como ferramenta de avaliação seu potencial pedagógico precisa ser muito bem explorado/planejado, com atividades instigantes, que contenham critérios de avaliação e objetivos de aprendizagem claramente definidos e, especialmente, que conte com a mediação docente norteando e estimulando a participação ativa e autônoma dos estudantes. Nesse sentido, acredito que o fórum de discussão pode ser uma importante ferramenta de avaliação da aprendizagem, porém tenho clareza que o seu uso sem intencionalidade pedagógica clara poderá trazer limitações ao processo ensino e aprendizagem, com consequências à avaliação. (TG)

Tendo em vista o exposto, destaca-se a opinião de Filatro (2008, p. 131) a qual ressalta que "no aprendizado eletrônico, a avaliação deve, portanto, estar fundamentada em uma clara abordagem pedagógica/andragógica, com critérios e padrões transparentes para os alunos". Kenski, Oliveira e Clementino (2006) lembram o quanto é importante a intervenção do tutor nas discussões dos fóruns. Os autores ressaltam que as contribuições dos alunos são bastante variadas e costumam estarem relacionadas tanto aos objetivos do curso, quanto às suas experiências profissionais e pessoais. Há, portanto, intensa troca de ideias e cabe ao tutor utilizá-las adequadamente para dar suporte a sua avaliação, a qual deve ter objetivos evidentes, de modo que os alunos compreendam como e quais aspectos serão avaliados. Os 
autores e a autora reafirmam o comentário supracitado do participante TG ao dizerem que os critérios de avaliação em um fórum de discussão precisam ser bem definidos e apresentados previamente aos acadêmicos, especialmente por se tratar de uma avaliação de caráter subjetivo.

A utilização do fórum como instrumento de avaliação necessita ser compreendida em um processo que exige mediação pelo tutor, além de possibilitar a realização de avaliação formativa e acompanhamento do desenvolvimento cognitivo do aluno. Faz-se importante considerar que "a avaliação em EaD é um processo dinâmico, aberto e contextualizado, que ocorre num período, não sendo uma ação pontual e isolada" como assim assegura Polak (2009, p. 154).

No grupo de acadêmicos, foi unânime considerarem o fórum de discussão como uma boa ferramenta de avaliação da aprendizagem e apresentaram justificativas diversas que muito se assemelham com aquelas apresentadas pelo grupo de tutores: permite ao tutor conhecer o ponto de vista dos alunos sobre o assunto abordado e acompanhar as discussões do grupo; proporciona a interação; permite espaço para sanar dúvidas, viabiliza troca de experiências e permite acompanhar o desenvolvimento dos alunos. O respondente A6 sinalizou que, embora seja uma boa ferramenta para avaliação da aprendizagem, alguns cursos apresentam fóruns com temáticas repetitivas e pouco produtivas. Outro participante considera positivo o uso da referida ferramenta no processo avaliativo, desde que haja "acompanhamento do tutor e estímulos ao aprofundamento da questão" (A7).

Dentre os aspectos sinalizados tanto pelos tutores, quanto pelos alunos, percebeu-se que a avaliação baseada na interação, troca de experiências e conhecimentos numa relação dialógica entre pares proporcionada pelo fórum de discussão é considerada instrumento positivo para acompanhar a aprendizagem e desenvolvimento dos aprendizes. As respostas dos participantes vão ao encontro com a literatura na qual os cursos à distância se baseiam para estruturar sua metodologia, ou seja, pautada no interacionismo. A esse respeito, a interação entre os sujeitos é considerada primordial no processo construtivo e a mediação por meio da linguagem faz parte desta interação para o estabelecimento de uma interlocução entre o saber sistematizado e o não sistematizado. "Nesse sentido, a intervenção pedagógica provoca avanços no processo de aprender que não ocorreriam espontaneamente" (TAILLE; OLIVEIRA; DANTAS, 1992, p. 33).

Partindo-se do princípio que mediação está entre dois pontos. Nesse sentido, tanto o professor tutor como os estudantes são elementos importantes na construção e reconstrução dessa teia de criação de significados. A qualidade desse processo construtivo e avaliativo em relação aos fluxos das interações, a partir dos diálogos estabelecidos dependerá do compromisso com o desenvolvimento intelectual do sujeito em relação a si mesmo e aos outros. Entrelaçamento este, resultante de conhecimentos teóricos e práticos entre os envolvidos nestes processos, influenciando-se mutuamente pelas idéias e relações com o outro, transformando-se e se autotransformando mediante posturas reflexivas.

Para tanto, isso exige a criação, por parte dos tutores, de contextos mais dinâmicos e flexíveis, cooperativos, solidários e abertos. Uma mediação pedagógica no sentido de enfatizar e valorizar a presença enriquecedora do outro, a humildade e a abertura para outras novas 
formas de conhecer baseadas em concepções paradigmáticas inovadoras. Reconhecimento das múltiplas realidades presentes nesses processos de ensino-aprendizagem, da presença do acaso, provisoriedade do conhecimento, sobretudo, valorizar a humildade de seus interlocutores como porta de entrada para a sabedoria.

\subsection{Critérios para Avaliação da Aprendizagem por meio do Fórum de Discussão}

Os participantes do grupo de tutores, quando perguntados sobre os critérios estabelecidos para avaliação da aprendizagem por meio do fórum de discussão responderam:

- Conteúdo que o aluno postou com relação ao tema discutido;

- Discurso do aluno baseado nos textos indicados para leitura.

- Interação;

- Participação;

- Qualidade da interação com os colegas;

- Nível de aprofundamento do tema;

- Alinhamento do comentário com o conteúdo trabalhado no ambiente virtual;

- Qualidade e pertinência dos argumentos apresentados.

Um dos tutores pesquisados destacou os itens de uma rubrica de avaliação, comumente utilizada para direcionar a avaliação das participações em fórum de discussão:

- $\quad 0 \%$ Passivo: só recebe as mensagens e não participa da discussão.

- $25 \%$ : Contribuição pontual isolada: cita definições diversas, mas não articula sua posição.

- $50 \%$ - Contribuição questionadora: propõe dilemas, apresentam alternativas e pede posicionamentos.

- 75\% - Contribuição debatedora: comenta contribuições anteriores com propriedade, responde a questionamento ou apresenta contra-argumento (pró e contra).

- $100 \%$ - Contribuição sintetizadora: posiciona sobre o tema, dialoga com os colegas, coleta segmentos da discussão, ajusta, adapta e elabora parecer sobre o tema. (TE)

Dada a necessidade de se estabelecer os critérios necessários para avaliação da aprendizagem em fórum de discussão e considerando as atribuições do tutor neste processo, Filatro (2008) sinaliza que o feedback permite ao aluno ampliar sua aprendizagem, além de representar oportunidade para concretizar saberes aprendidos e desenvolver habilidades metacognitivas.

Em síntese, a avaliação em fóruns de discussão deve ser percebida como um processo além do simples objetivo de se obter resultados de aprovação, proporcionando ao aluno uma percepção reflexiva sobre o seu próprio modo de aprender.

Como exemplo de rubricas de avaliação, destaca-se a proposta de Silva, contendo itens como:

Participar de todos os fóruns da disciplina; Trazer para os debates suas inquietações, experiências de vida e profissional bem como contribuições 
advindas de pesquisas a partir de várias fontes (internet, leituras, movimentos sociais, ciência, etc.); comentar mensagens dos e das demais aprendentes, interagindo e fazendo intervenções que dinamizaram os debates nos fóruns; Participar de forma crítica e ética, com respeito e tolerância à pluralidade dos discursos que emergiam dos debates e embates (SILVA, 2009, p. 157).

Já o grupo de acadêmicos apresentou como respostas:

- Contribuição com o assunto.

- Participação efetiva.

- Assiduidade.

- Aprofundamento do tema.

- Participação diária.

- Construção do conhecimento alinhado aos objetivos do curso.

- Interação com o grupo e com o tutor.

- Rubricas de avaliação.

A partir destas respostas dos participantes se observa que estabelecer critérios de avaliação por parte do tutor e levá-los ao conhecimento dos alunos é um procedimento indispensável para utilização do fórum de discussão como instrumento de avaliação. Os critérios norteiam a avaliação do tutor, que passa a ter como base aspectos qualitativos específicos. Além disso, também se transformam em uma espécie de guia do aluno para direcionar sua participação, auxiliando-os na escolha de elementos que consideram mais relevantes estarem presentes em suas respostas. Acredita-se, ainda, que a definição de critérios estimule os alunos a serem mais cautelosos antes de publicarem suas respostas, dando-os condições de serem mais assertivos e apresentarem publicações mais completas, atendendo ao solicitado pelo professor e contribuindo para uma qualidade produtiva em relação aos saberes necessários para o desenvolvimento da aprendizagem em seu percurso construtivo de conhecimentos pertinentes tanto à vida pessoal quanto profissional.

\subsection{Aspectos Positivos a Respeito da Utilização do Fórum de Discussão como Instrumento de Avaliação da Aprendizagem}

Para a construção da listagem de atributos de aspectos positivos e negativos do fórum de discussão como instrumento de avaliação foi solicitado aos participantes que apresentassem no mínimo três aspectos de cada. A partir da percepção dos participantes, construiu-se a seguinte listagem, contendo atributos ligados a aprendizagem, atuação do tutor e interação/participação: 
Quadro 1 - Aspectos Positivos do Fórum de Discussão como Instrumento de Avaliação.

\begin{tabular}{|c|c|c|c|}
\hline & Atributos ligados à aprendizagem & Atributos ligados à atuação do tutor & $\begin{array}{c}\text { Atributos ligados à relação entre os } \\
\text { participantes }\end{array}$ \\
\hline Tutores & $\begin{array}{l}\text { - Possibilita redimensionar os processos de ensino e } \\
\text { aprendizagem e potencializar diferentes estratégias } \\
\text { para levar o estudante a pesquisar, aprofundar-se, } \\
\text { trocar experiências, aprender em colaboração com o } \\
\text { outro. } \\
\text { - Pode-se avaliar o interesse do aluno pelo tema. } \\
\text { - Permite aos próprios estudantes um acompanhamento } \\
\text { quanto ao seu desenvolvimento e promove o } \\
\text { autoconhecimento em relação ao próprio processo } \\
\text { construtivo de conhecimento. } \\
\text { - Possibilita a autonomia e possivelmente a autoria, } \\
\text { tornando o sujeito mais ativo, disciplinado e } \\
\text { responsável pelo próprio desenvolvimento e } \\
\text { construção das ideias, e materialização destas pela } \\
\text { escrita, ajudando a estruturar melhor o pensamento e } \\
\text { a linguagem. } \\
\text { Possibilita o compartilhamento de arquivos multimidia } \\
\text { como recursos norteadores do debate. }\end{array}$ & $\begin{array}{l}\text { - Percepção do tutor em relação à } \\
\text { participação e forma de demonstrar o } \\
\text { conhecimento do aluno. } \\
\text { Permite ao educador acompanhar o } \\
\text { progresso dos estudantes quanto a a } \\
\text { mudanças no que diz respeito à } \\
\text { produção do conhecimento, articulação } \\
\text { de ideias e pensamentos. }\end{array}$ & $\begin{array}{l}\text { - Troca de experiências e conhecimentos entre } \\
\text { alunos e/ou alunos-professor. } \\
\text { - Interação aluno-aluno. } \\
\text { - Permite gerar discussões acerca de um } \\
\text { determinado assunto. } \\
\text { - Possibilita debates e discussões com elevado } \\
\text { grau de amplitude. } \\
\text { - Os questionamentos do grupo viabilizam } \\
\text { conhecimento adicional ao tema. } \\
\text { - Possibilita avaliar o "clima" da turma em } \\
\text { relação à participação nas aulas. } \\
\text { A logistica geográfica não é um empecilho, } \\
\text { tendo em vista que é sanada pelas facilidades } \\
\text { da internet. }\end{array}$ \\
\hline Acadêmicos & $\begin{array}{l}\text { É possivel avaliar respostas de questões abertas } \\
\text { Estimula novas rotinas de estudo, tendo em vista a } \\
\text { necessidade de ler as postagens dos colegas antes de } \\
\text { emitir uma opinião ou iniciar a participação. } \\
\text { Estimula a busca pelo conhecimento. } \\
\text { - Permite sintetizar os conteúdos/temas apresentados. } \\
\text { Alinha o conhecimento junto ao tutor e demais } \\
\text { colegas. } \\
\text { - Permite acesso a novos conteúdos intermediados por } \\
\text { novas pesquisas sobre o tema. } \\
\text { - As respostas ficam registradas e permitem posterior } \\
\text { - Peitura do que fol discutido. } \\
\text { - Permite o aluno ser avaliado ao longo do estudo e não } \\
\text { - Pode-se avaliar o nivel de aprendizagem do aluno. }\end{array}$ & & 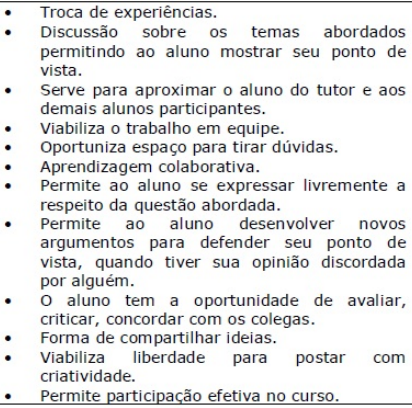 \\
\hline
\end{tabular}

Fonte: próprio autor.

Percebeu-se nas respostas tanto dos tutores, quanto dos acadêmicos que a utilização do fórum de discussão como instrumento de avaliação potencializa a aprendizagem por meio da relação e discussão entre os participantes. Nessa perspectiva, a aprendizagem por meio da relação entre os participantes se fundamenta em Vygotsky $(2007,2008)$, para quem o sujeito aprende em relação com a cultura ao longo de seu desenvolvimento mediante a internalização de situações vividas e observadas através da fala e confrontos com o outro. Nesse processo as atividades interpessoais, transformam-se em intrapsicológicas, demonstrando que o desenvolvimento pode se dar de fora para dentro à medida que a linguagem e o pensamento vão se desenvolvendo e conforme a consciência vai se formando dialeticamente.

Nesse processo de aprender na relação com os outros o sujeito aprimora as estruturas mentais, construindo-se por meio da rede relacional novos conceitos, tanto no nível social quanto individual. Visto que, o conhecimento não está no sujeito nem no objeto, mas no espaço interacional constituído entre ambos. Ao agir sobre os objetos e sofrendo a ação destes, os sujeitos da práxis ampliam a capacidade de conhecer, de vivenciar processos de aprendizagem. Nesta dinâmica, o sujeito é ativo, pois à medida que se relaciona e se comunica, desenvolve-se cultural e socialmente.

Em outra abordagem, Almeida (2011) sinaliza que a interação estabelecida nos ambientes virtuais de aprendizagem permite que se realizem mediações entre os participantes, o meio social e o próprio ambiente, intensificando as articulações que se estabelecem na experiência social.

Ainda no que se refere aos resultados do estudo, percebeu-se que os atributos ligados aos aspectos positivos demonstraram que a utilização do fórum de discussão como instrumento de 
avaliação viabiliza uma gama de benefícios, especialmente aqueles relacionados aos atributos de aprendizagem e de interação/participação, permitindo que a avaliação seja percebida em uma relação dialógica. Nessa perspectiva, Hoffmann (1994) sinaliza que a avaliação deve ser executada de modo que promova ação-reflexão-ação, estimulando o desenvolvimento de saberes significativos. Esse movimento, promovido pela relação dialógica, permite ao docente refletir a respeito de como ocorre a compreensão do aluno sobre o objetivo de conhecimento e intervir com situações de aprendizagem que o leve para outro nível de percepção e conhecimento em relação a realidade e a formação da consciência.

Romão (2011) defende que a avaliação numa perspectiva dialógica consiste em uma atividade cognoscitiva, na qual tutor e estudantes dialogam buscando reconstruir o conhecimento, pois o compreendem como um processo de descoberta coletiva, momento de aprendizagem para ambos, com vistas a superar a dicotomia existente entre estático/dinâmico, o existente/o desejado, o produto/processo. Nesta perspectiva o caráter da avaliação passa a ser interpretada como um desafio que provoca o sujeito a tornar-se mais, atuando como protagonista de sua própria história construtiva de conhecimentos.

\subsection{Aspectos Negativos ou que Precisam ser mais bem Explorados a Respeito da Utilização do Fórum de Discussão como Instrumento de Avaliação da Aprendizagem}

A respeito dos aspectos negativos, solicitou-se aos participantes do estudo que sinalizassem três opções e a partir das respostas obtidas se construiu a seguinte listagem de atributos, divididas em áreas ligadas a aprendizagem, atuação do tutor, interação/participação, design instrucional e relação interpessoal: 
Quadro 2 - Aspectos Negativos do Fórum de Discussão como Instrumento de Avaliação.

\begin{tabular}{|c|c|c|c|c|c|}
\hline & $\begin{array}{c}\text { Atributos ligados a } \\
\text { aprendizagem }\end{array}$ & $\begin{array}{l}\text { Atributos ligados a } \\
\text { atuação do tutor }\end{array}$ & $\begin{array}{c}\text { Atributos ligados à } \\
\text { interação/participação }\end{array}$ & Design instrucional & $\begin{array}{c}\text { Relação entre os } \\
\text { participantes }\end{array}$ \\
\hline Tutor & $\begin{array}{l}\text { - Uma discussão de } \\
\text { troca de ideias não mede } \\
\text { conhecimento absorvido. } \\
\text { - O fórum é para todos } \\
\text { e as avaliações diferem } \\
\text { de pessoa por pessoa. } \\
\text { - A utilização do fórum } \\
\text { como meio de avaliação } \\
\text { pode inibir o aluno. } \\
\text { - A superficialidade das } \\
\text { opiniões, muitas vezes } \\
\text { atendo-se somente a } \\
\text { responder as questões } \\
\text { problematizadoras. } \\
\text { - Respostas curtas e } \\
\text { sem conteúdo quando a } \\
\text { temática } \\
\text { desinteressante ou } \\
\text { pouco desafiadora; ou }\end{array}$ & $\begin{array}{l}\text { - O fórum é muito bom para } \\
\text { interação, porém, a } \\
\text { avaliação do conteúdo } \\
\text { postado deve ser realizada } \\
\text { pelo tutor de forma } \\
\text { individual, o que toma } \\
\text { muito tempo. } \\
\text { - Interpretação equivocada } \\
\text { por parte dos alunos se as } \\
\text { orientações não estiverem } \\
\text { bem elaboradas ou } \\
\text { direcionadas. } \\
\text { - A participação do Tutor } \\
\text { deve ser mais ativa. } \\
\text { - Subjetividade nas } \\
\text { avaliações por parte do } \\
\text { tutor. } \\
\text { - Mensurar de forma objetiva } \\
\text { é dificil. } \\
\text { - Entendimento do aluno em } \\
\text { relação ao objetivo do } \\
\text { fórum, pois é fácil encontrar } \\
\text { respostas corretas para a } \\
\text { pergunta errada. } \\
\text { - Planejamento do fórum } \\
\text { tende a ser mais moroso e } \\
\text { avaliação mais demorada. } \\
\text { - Possibilidade de fugir do } \\
\text { foco da atividade } \\
\text { (dispersão). }\end{array}$ & $\begin{array}{l}\text { - A falta de interatividade } \\
\text { entre os participantes do } \\
\text { fórum, dialogando uns com } \\
\text { os outros a partir das } \\
\text { opiniões, visto que, a } \\
\text { qualidade dos fóruns } \\
\text { depende da qualidade das } \\
\text { interações. } \\
\text { - Apesar de ser uma } \\
\text { ferramenta assíncrona, a } \\
\text { participação ativa e a } \\
\text { presença virtual dos } \\
\text { participantes é fundamental } \\
\text { para que os diálogos } \\
\text { aconteçam com conexão e } \\
\text { sentido entre as falas e } \\
\text { conforme se vai costurando } \\
\text { as discussões. } \\
\text { - A interação entre as } \\
\text { pessoas ocorre somente no } \\
\text { universo virtual, faltando o } \\
\text { "calor humano" quando se } \\
\text { debate ou discute um } \\
\text { determinado tema; } \\
\text { - Timidez (perfil) de alguns } \\
\text { alunos para atividades que } \\
\text { pressupõe interação. } \\
\text { - Falta de garantia de } \\
\text { preparo do mediador para } \\
\text { gerenciar fóruns de de } \\
\text { discussão. } \\
\text { - Subjetividade } \\
\text { avaliações por parte do } \\
\text { tutor. }\end{array}$ & & \\
\hline Acadêmicos & $\begin{array}{l}\text { - Quando o grupo não tem } \\
\text { o mesmo nivel de } \\
\text { interesse e conhecimento. } \\
\text { - Discussões sem } \\
\text { aprofundamento, só pra } \\
\text { ganhar a pontuação. }\end{array}$ & $\begin{array}{l}\text { - Demora nas respostas por } \\
\text { parte do tutor. } \\
\text { - Falta de intervenção mais } \\
\text { pontual do tutor com } \\
\text { relação a respostas } \\
\text { inconsistentes de alguns } \\
\text { alunos. } \\
\text { - A avaliação é bastante } \\
\text { subjetiva. } \\
\text { - Demora do feedback aos } \\
\text { alunos. } \\
\text { - Mediação pouco produtiva } \\
\text { por parte do tutor. } \\
\text { - Discussões com baixa } \\
\text { mediação do tutor para } \\
\text { direcionar e enriquecer as } \\
\text { discussões. }\end{array}$ & 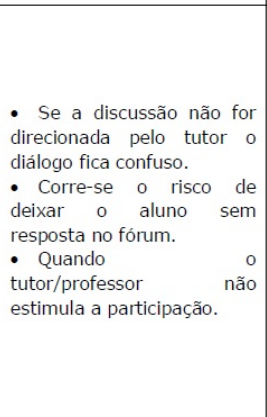 & $\begin{array}{l}\text { - Questões mal } \\
\text { elaboradas que não } \\
\text { permitem debates. } \\
\text { - Em alguns momentos } \\
\text { a discussão sai do foco. } \\
\text { - Não ter uma } \\
\text { ferramenta, sempre } \\
\text { disponivel, para vídeo } \\
\text { conferências. } \\
\text { - Às vezes os assuntos } \\
\text { parecem repetitivos. } \\
\text { - Material extenso e } \\
\text { pouco motivador. }\end{array}$ & $\begin{array}{l}\text { - Não poder ver os } \\
\text { colegas } \\
\text { fisicamente. } \\
\text { - Ausência de } \\
\text { afetividade. } \\
\text { - Não poder ouvir e } \\
\text { falar com as } \\
\text { pessoas. }\end{array}$ \\
\hline
\end{tabular}

Fonte: próprio autor.

Dentre os aspectos negativos apontados pelos dois grupos, percebeu-se que a maioria das respostas estão associadas à mediação do tutor, o que permite a interpretação de que a atuação deste profissional é um dos pontos primordiais para o sucesso de uma avaliação por meio do fórum de discussão. Dentre os atributos mencionados, destacam-se: Falta de preparo do mediador para gerenciar fóruns de discussão; discussões com baixa mediação do tutor para direcionar e enriquecer as discussões; mediação pouco produtiva por parte do tutor; falta de intervenção mais pontual do tutor com relação a respostas inconsistentes de alguns alunos.

Masetto (2000, p. 144) entende que a mediação do tutor é “a atitude, o comportamento do professor que se coloca como um facilitador, incentivador ou motivador da aprendizagem, que se apresenta com a disposição" de ser uma ponte rolante e não estática, colaborando ativamente para que os estudantes alcancem seus objetivos. A esse respeito Lévy (1999) ressalta que o professor, no contexto de mediação da aprendizagem por meios tecnológicos, deve perceber que sua competência se desloca para o incentivo da aprendizagem e do pensamento. De acordo com o autor, nessa perspectiva o docente: assume o papel de 
animador da inteligência coletiva; concentra-se no acompanhamento e no gerenciamento da aprendizagem, estimulando a troca de conhecimentos; viabiliza condições para que a relação entre os indivíduos e os percursos de aprendizagem personalizados ocorra de forma significativa.

Souza e outros (2004) acrescentam que o tutor deve desenvolver habilidades de comunicação específicas e características desejáveis e esperadas ao perfil de um tutor, sendo: liderança, bom relacionamento interpessoal, dinamismo, iniciativa, entusiasmo, criatividade e habilidade para trabalhar em equipes. Gonzalez (2005, p.71) também apresenta algumas características desejadas para o tutor online:

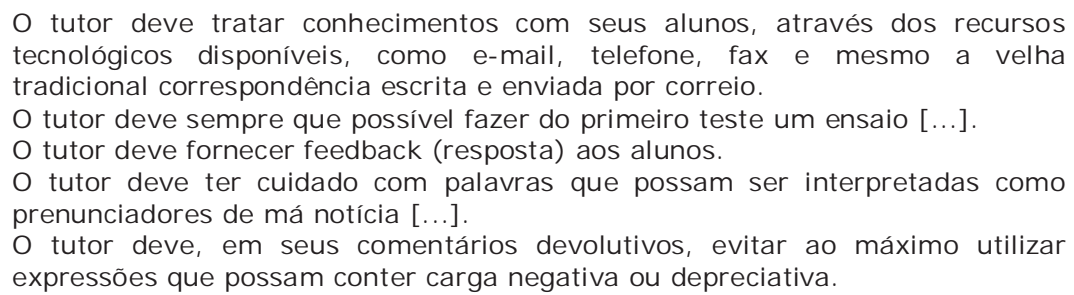

Nessa perspectiva Mercado (2006, p. 147) destaca que o tutor também tem uma função gerencial, citando que esse deve ter “[...] capacidade de gerenciar equipes e administrar talentos, habilidades de criar e manter o interesse do grupo pelo tema; ser motivador e empenhado em acompanhar a aprendizagem dos alunos". Ainda a esse respeito, Barbosa (2012) ressalta que o tutor precisa: fazer melhor aproveitamento dos meios de comunicação online, de modo que permitam o desenvolvimento de uma aprendizagem mais autônoma do aluno; desenvolver estratégias que viabilizem o acompanhamento do estudante.

Assim, o papel da tutoria é o de ensinar, bem como o de orientar e acompanhar o desenvolvimento dos estudantes em um ambiente dinâmico possibilitado pelas tecnologias para uma aprendizagem significativa capaz de trazer sentido tanto a vida pessoal, profissional e social do sujeito aprendiz. O bom tutor não é aquele que mostra a resposta ao aluno, mas aquele capaz de elaborar novas perguntas no sentido de fazer exercitar o pensamento crítico sobre o assunto discutido, oferecer fontes de informação para dinamizar o processo de construção de conhecimento por parte dos alunos, mantendo-os o tempo todo em movimento de aprendizagem, desaprendizagem e reaprendizagem, sobretudo, de apoiar o aluno na resolução das atividades desafiadoras propostas para que avance rumo a novos processos no que diz respeito ao conhecimento.

Em continuidade à análise dos resultados obtidos quanto aos aspectos negativos apresentados no Quadro 2, observou-se que foram sinalizados alguns fatores associados ao DI (Design Instrucional). Embora tenham sido identificados poucos registros relacionados a esse aspecto, a reflexão se faz necessária quanto à qualidade das propostas de atividades, material de leitura e recursos a serem utilizados pelos alunos. Filatro (2008) aponta o design instrucional como um processo, desenvolvido por meio de um conjunto de atividades que buscam atender aos interesses inerentes à aprendizagem dos estudantes. Para tanto os procedimentos envolvem: desenhar, implementar e avaliar as soluções adotadas. A autora 
também destaca que o design instrucional está para além da apresentação estética de um produto instrucional, pois representa a estruturação de elementos que permitem o cumprimento dos objetivos educacionais previstos (FILATRO, 2007).

Em síntese, as ideias de Filatro $(2007 ; 2008)$ demonstram que o design instrucional do curso está diretamente ligado à qualidade das atividades propostas aos alunos e, consequentemente, aos resultados de aprendizagem, indo ao encontro com os resultados apresentados no Quadro 2. Por outro lado, destaca-se que a maior incidência de registros de aspectos negativos do fórum enquanto instrumento de avaliação da aprendizagem se refere aos atributos de aprendizagem, atuação do tutor e interação.

\section{Considerações Finais}

Os resultados do estudo demonstraram que o fórum de discussão é considerado pela maioria dos respondentes um bom instrumento de avaliação, que muito pode colaborar para melhorar a qualidade da aprendizagem dos estudantes, quando estes conhecem os critérios a serem levados em consideração durante o percurso da aprendizagem. Ele pode funcionar também como termômetro tanto para educadores como para educandos estarem revendo constantemente os próprios processos construtivos de conhecimentos. Além disso, por meio dos registros publicados nos fóruns a partir da relação dialógica entre os estudantes e tutores é possível identificar as dificuldades encontradas durante o desenvolvimento do curso e possibilitar as condições necessárias para o educador atuar no sentido de intervir, buscando encontrar saídas, situações didáticas que visem maximizar tais processos e favorecer situações que desloquem os estudantes para outros níveis de percepção e conhecimento em relação à realidade e formação da consciência.

Neste sentido, a avaliação deve ser compreendida como função formadora com vistas a proporcionar a ocorrência de processos de autoorganização nos sujeitos da práxis pedagógica, bem como colaborar para o desenvolvimento de suas capacidades de aprender a aprender mediante o pensar sobre o próprio pensar.

A clareza quanto aos critérios de avaliação da aprendizagem adotados foi um aspecto muito mencionado. Paralelo a isso, notou-se por parte dos dois grupos pesquisados, ênfase na importância da intervenção do tutor para que o processo de ensino e aprendizagem promovidos com o uso do fórum de discussão se construa positivamente e a aprendizagem aconteça.

As respostas dos participantes proporcionaram reflexão e constatação da opinião das autoras a respeito da atuação do tutor no processo de avaliação da aprendizagem por meio de fóruns de discussão. Considera-se que a participação ativa desse profissional e sua relação com os alunos estão diretamente ligados aos resultados de aprendizagem.

Pretende-se que os critérios considerados mais apropriados para a avaliação da aprendizagem em fórum de discussão e a listagem de atributos ligada a aspectos positivos e negativos, construída a partir da percepção de estudantes e tutores, proporcione aos docentes novas reflexões/ações no exercício da docência online no sentido de permitir que a aprendizagem seja a tônica máxima na dinâmica do ensinar e aprender, possibilitando cada vez 
mais a aproximação entre o processo do ensino (docência) do processo da aprendizagem (estudantes) nos ambientes de aprendizagem.

\section{Referências}

ALMEIDA, Maria Elizabeth Bianconcini de. Educação, Ambientes Virtuais e Interatividade. In: SILVA, Marco (Org.) Educação Online: teorias, práticas, legislação, formação corporativa. São Paulo: Loyola, 2011.

BARBOSA, Cláudia Maria Arôso Mendes. A Aprendizagem Mediada por TIC: interação e cognição em perspectiva. Revista Brasileira de Aprendizagem Aberta e a Distância, v. 11, p. 83-100, 2012.

BRASIL. Decreto № 5.622, de 19 de dezembro de 2005. Diário Oficial [da] República Federativa do Brasil. Brasília, DF, 19 dez. 2005. Disponível em: <http://www.planalto.gov.br/ccivil_03/_ato20042006/2005/Decreto/D5622.htm>. Acesso em: 8 maio 2014.

. Lei de Diretrizes e Bases da Educação Nacional. Lei № 9.394, de 20 de dezembro de 1996. Diário Oficial [da] República Federativa do Brasil. Brasília, DF: Ministério da Educação, 1996. Brasília, DF, 20 dez. 1996. Disponível em: <http://portal.mec.gov.br/arquivos/pdf/ldb. pdf>. Acesso em: 8 maio 2014.

Referências de Qualidade para a Educação Superior a Distância. Brasília, DF: Ministério da Educação/Secretaria de Educação a Distância, 2007.

CRESWELL, John W. Projeto de Pesquisa: métodos qualitativo, quantitativo e misto. Tradução Luciana de Oliveira da Rocha. 2. ed. Porto Alegre: Artmed, 2007. 248 p.

DIAS, Rosilâna Aparecida; LEITE, Lígia Silva. Educação a Distância: da legislação ao pedagógico. Petrópolis: Vozes, 2010.

FILATRO, Andrea. Design Instrucional Contextualizado. São Paulo: Senac, 2007.

Design Instrucional na Prática. São Paulo: Pearson Education do Brasil, 2008.

FRANCO, Maria Laura Puglisi Barbosa. Análise de Conteúdo. Brasília: Liber Livro, 2005.

GONZALEZ, Mathias. Fundamentos da Tutoria em Educação a Distância. São Paulo: Avercamp, 2005.

HOFFMANN, Jussara. Avaliação, Mito e Desafio: uma perspectiva construtivista. Porto Alegre: Mediação, 2005.

. Avaliação Mediadora: uma relação dialógica na construção do conhecimento. Série Idéias, São Paulo: FDE, n. 22, 1994. P. 51-59.

KENSKI, Vani Moreira; OLIVEIRA, Gerson Pastre de; CLEMENTINO, Adriana. Avaliação em Movimento: estratégias formativas em cursos online. (Org.). SILVA, Marcos; SANTOS, Edméa. Avaliação da Aprendizagem em Educação Online: fundamentos, interfaces e dispositivos, relatos de experiências. São Paulo: Loyola, 2006.

KRATOCHWILL, Susan. Avaliação da Aprendizagem em uma Perspectiva Dialógica a partir do Fórum Online. In: SILVA, Angela Carrancho (Org.). Aprendizagem em Ambientes Virtuais e Educação a Distância. Porto Alegre: Mediação, 2009. P. 135-168.

LÉVY, Pierre. Cibercultura. São Paulo: Editora 34, 1999.

MASETTO, Marcos T. Mediação Pedagógica e o Uso da Tecnologia. In: MORAN, José Manuel (Org.). Novas Tecnologias e Mediação Pedagógica. Campinas, SP: Papirus, 2000. 
MERCADO, Luís Paulo Leopoldo. Tutoria no Curso TV na Escola e os Desafios de Hoje. In: Experiências com Tecnologias de Informação e Comunicação na Educação. Maceió: Edufal, 2006.

PALLOF, Rena; PRATT, Keith. O Aluno Virtual: um guia para trabalhar com estudantes online. Porto Alegre: Artmed, 2004.

POLAK, Ymiracy Nascimento de Souza. A Avaliação do Aprendiz em EaD. In: LITTO, Frederic M.; FORMIGA, Marcos (Org.). Educação a Distância: o estado da arte. São Paulo: Pearson, 2009. P. 153-160.

ROMÃO, José Eustáquio. Avaliação Dialógica: desafios e perspectivas. 9. ed. São Paulo: Cortez, 2011.

SALVUCCI, Mara; LISBOA, Marcos J. A.; MENDES, Nelson C. Educação a Distância no Brasil: fundamentos legais e implementação. Revista Brasileira de Aprendizagem Aberta e a Distância, v. 11, p. 49-62, 2012.

SANTOS, Edméa. Avaliação da Aprendizagem em Educação Online. São Paulo: Loyola, 2006. P. 79 - 89.

SILVA, Angela Carranho. Aprendizagem em Ambientes Virtuais e Educação a Distância. Porto Alegre: Mediação, 2009.

SILVA, Marcos. Educação Online: teorias, práticas, legislação, formação corporativa. São Paulo: Loyola, 2003.

SOUZA, Carlos Alberto de. et. al. Tutoria na Educação a Distância. CONGRESSO ABED 2004. [Anais eletrônicos...] Disponível em: <http://www.abed.org.br/congresso2004/por/htm/088-TC-C2.htm>. Acesso em: 4 de out. 2014.

TAILLE, Yves Ia; OLIVEIRA, Marta Kohl; DANTAS, Heloysa. Piaget, Vygotsky, Wallon: teorias psicogenéticas em discussão. São Paulo: Summus, 1992.

VYGOTSKY, Lev Semenovitch. A Formação Social da Mente: o desenvolvimento dos processos psicológicos superiores. 7. ed. São Paulo: Martins Fontes, 2007.

Pensamento e Linguagem. 4. ed. São Paulo: Martins Fontes, 2008.

Recebido em 26 de fevereiro de 2016

Aprovado para publicação em 16 de abril de 2016

\section{Alexandra da Costa Souza Martins}

SENAC-DF, Brasília, Brasil, profalexandra13@hotmail.com

Lucicleide Araújo de Sousa Alves

Universidade Católica de Brasília, Brasília, Brasil, lucicleide.ead@gmail.com 